\title{
Spatial and Temporal Clustering of Fault Events on the GB Transmission Network
}

\author{
Euan A. Morris \\ Future Power Networks and Smart Grids CDT \\ University of Strathclyde \& Imperial College London \\ Glasgow, UK \& London, UK \\ euan.a.morris@ieee.org
}

\author{
Keith R.W. Bell \& Ian M. Elders \\ Department of Electronic \& Electrical Engineering \\ University of Strathclyde \\ Glasgow, UK \\ keith.bell@strath.ac.uk \\ i.elders@strath.ac.uk
}

\begin{abstract}
The UK is subject to changing weather patterns due to the global process of climate change. The full extent of these changes is not currently known; however, it is possible that the UK will be subject to more extreme or more frequent severe weather events (or both). As $50 \%$ of the faults on the transmission network in Britain are weather related it is likely that any change in weather patterns for the worse would increase the number of faults the network experiences. This paper describes a review of fault records in one region of the $U K$ in order to understand the potential impact on system operation of clusters of weather related network faults. Based on the patterns of identified clusters, it suggests some potential impacts of climate change.
\end{abstract}

Index Terms - Adverse or Extreme Weather, Fault Outages, GB Transmission Network

\section{INTRODUCTION}

$\mathrm{I}$ $\mathrm{N}$ the UK, around $50 \%$ of transmission faults are caused in some manner by the weather. Faults, abnormal currents which cause a piece of equipment or circuit to be automatically or manually switched out of service, can be caused by a range of weather events[1]. High wind speeds can damage overhead lines by causing conductor galloping and, as a consequence, short circuits, mechanical failure of insulator fittings or cross arms, trees or debris to fall onto the lines or, in extreme cases, poles or towers to fail. Ice and snow can also impact overhead lines, with additional weight from ice or snow build-up causing aerofoil effects in high winds leading to short circuits, lines and towers to fall, or on occasion, trees to fall onto them. Lightning strikes can produce ionised gases, which if near overhead line conductors can provide a current path causing a flashover, which activates automatic protection systems. If lightning strikes the conductors themselves this can cause a voltage surge, which can affect equipment connected to the lines, such as transformers.

As the effects of climate change begin to be felt, it is likely that the weather in the UK will change significantly, either with more frequent occurrences of severe weather, or with weather

This work was supported through the EPSRC Centre for Doctora Training in Future Power Networks and Smart Grids, grant number EP/L015471/1. events with greater extremes. There have been many studies

that have been performed on the potential impact of climate change on various aspects of the UK from food security, to flooding. The UK Meteorological Office [2] suggests that, over the coming century, Britain will see temperature rises of around $3{ }^{\circ} \mathrm{C}$ based on the Intergovernmental Panel on Climate Change's Special Report on Emissions Scenarios scenario A1B[3], which is broadly central among IPCC emissions scenarios. If this is the case, there could be a significant impact on operation of the power system. Research has been conducted into how these changes might affect electricity networks throughout the world, particularly North America[1][4] and the Nordic countries [5]. Potential effects include increased demand for cooling services in summer, reduced line and transformer ratings, impacts on the efficiency of thermal generating plant and changed patterns of power available from weather-dependent renewables as well the possibility of increased numbers of weather-related faults[6]. Under extreme high temperature conditions, ecological considerations might cause thermal power plant dependent on rivers or lakes for cooling to shut down due to excessive water temperatures[7]. The impact of climate change on the UK's distribution network has also been explored [8]. However, the impact on the Great Britain (GB) transmission network has not been fully examined, with earlier research focused on the specific impact of wind related faults [9].

Discrete periods of adverse, severe or extreme weather caused by a particular weather system can be referred to as a single weather event. From a power system operation perspective, the severity of a particular weather event concerns the number of faults that occur in its course and the duration of the outages caused by the faults.

This paper considers past weather related faults, with a view to assessing the broad potential impact of a changing climate on the GB transmission grid. To achieve this transmission fault data for the ScottishPower Energy Networks (SPEN) transmission license area (located in the south of Scotland - see 
[10]) from 1985 - 2011 was analysed in an attempt to identify the network faults associated with different weather events and to understand the severity of each weather event. This was done firstly through temporal clustering of network faults and then by reviewing the number of faults in each cluster, the cluster's duration and its spatial extent. From this, the possible effect of climate change causing more such events or more severe events can be assessed.

The fault data from SPEN comprised: information about the date and time of the fault; the date and time of fault restoration; the circuits affected by the fault; whether the fault was permanent or transient; the type of equipment which faulted; the number of affected customers if there was a disconnection of demand; the voltage level the fault occurred at; and a brief description of the cause of the fault. In total the record detailed 3,066 faults. From the fault descriptions it was possible to separate the faults into weather related (1532) and non-weather related (1534). The weather related faults were then divided further into those caused by: ice, snow, sleet and blizzard (436); lightning (293); wind, gales, and windborne objects (619); and salt, corrosion, and condensation (129). The remaining faults, categorised as rain and flooding, pollution, mist and freezing fog, other weather types and fire not due to faults, (total 55), were not included in this study due to their small number.

The next section discusses the initial temporal clustering and the numbers of fault in each cluster. The durations of clusters and their spatial extent are discussed in sections III and IV. The main findings are discussed in section $\mathrm{V}$ before the presentation of some conclusions and recommendations for further work in section VI.

\section{TEMPORAL CLUSTERING}

In order to identify individual weather events, such as storms, which caused one or more weather-related faults, a cluster analysis was performed.

The clusters were identified in the data based on the date and time that the faults occurred. The length of time that a storm can last can vary from a few hours to days [1][5]. Thus, for consistency, for this analysis a weather event was considered finished if over 2 hours (taken as a minimum for the length of a storm) passed without another fault event in at least one of the same circuits [11]. From this: 70 ice, snow, sleet and blizzard, 161 lightning, 123 wind, gale, and windborne objects, and 61 condensation, corrosion, and salt clusters were found.

\section{A. Faults due to ice, snow, sleet and blizzards}

The size of the each of the clusters found in the ice, snow, sleet and blizzard data can be seen in Fig. 1. The largest cluster, cluster \#47, consists of 135 faults. This was caused by a large blizzard in 2001 affecting the circuits around the nuclear power station, Torness, and the coal-fired power station, Cockenzie, in the south-east of Scotland. Most other ice, snow, sleet or blizzard related events were smaller, with a large number containing only one fault. The average duration of ice, snow, sleet or blizzard related fault outages was 2 hours 20 minutes with the shortest lasting less than 1 minute and the longest 22 hours 51 minutes.

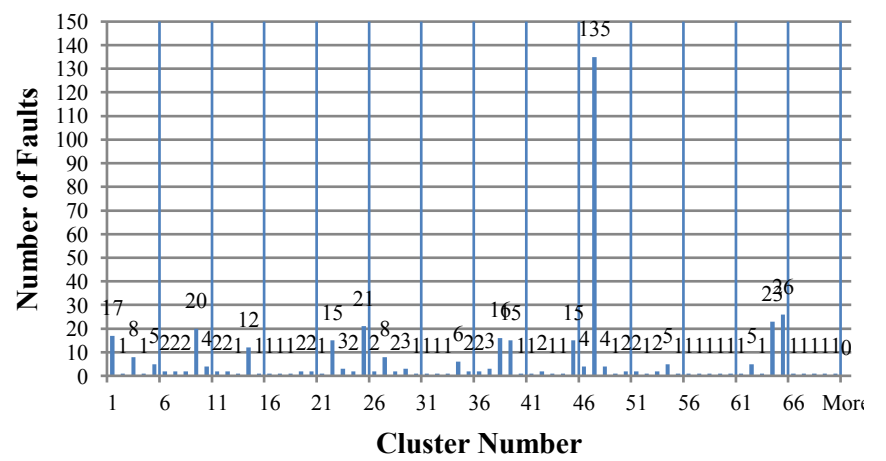

Fig. 1. Clusters in ice, snow, sleet and blizzard data.

A frequency distribution of the clusters can be seen in Fig. 2. From this it can be clearly seen that around half of the clusters contain only one fault, with one quarter consisting of only 2 . On average clusters contained around 6 faults.

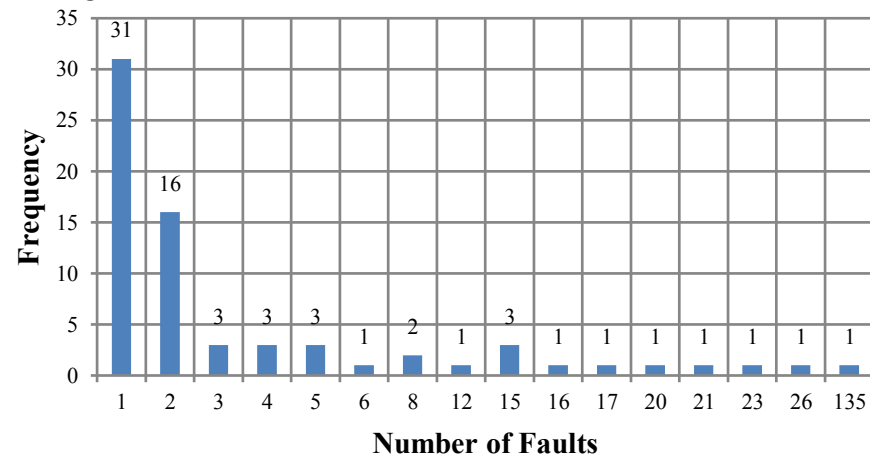

Fig. 2. Frequency distribution of size of ice, snow, sleet, and blizzard clusters

Statistical analysis [8] suggests that snow related faults are correlated with both daily maximum snowfall and daily maximum wind gusts. Although daily maximum wind gusts could potentially increase (although they may decrease or remain similar) [9], the daily maximum snowfall is expected to fall, with a decrease in days in which snow occurs [8]. This suggests that the severity and number of these types of weather events is likely to decrease, and therefore the total number of faults on the GB system due to ice, snow, sleet and blizzard is likely to decrease too. However, rare, severe events can still occur and, if there are more frequent high speed wind gusts, will see more faults during snow, ice or sleet related events and, potentially, mechanical damage (not just transient faults) with long circuit restoration times.

\section{B. Faults due to lightning}

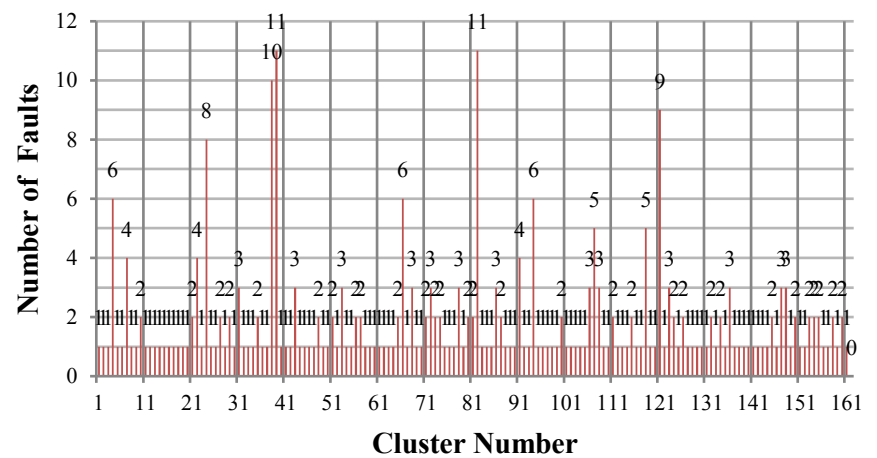

Fig. 3. Clusters in lightning data

Fig. 3 shows the clusters found for the data on faults due to lightning. Unlike in the ice, snow, sleet and blizzard data, there do not appear to be large lightning events which cause large 
numbers of faults. There are a few smaller events which cause 10 or more events, and several which cause 5 or more. A frequency distribution for these faults can be seen in Fig. 4. The average duration of individual lightning fault outages was 43 minutes. Only $8 \%$ of faults had an outage time greater than 120 minutes with longest restoration time among these being 22 days, due to damage to a transformer, which likely needed to be replaced.

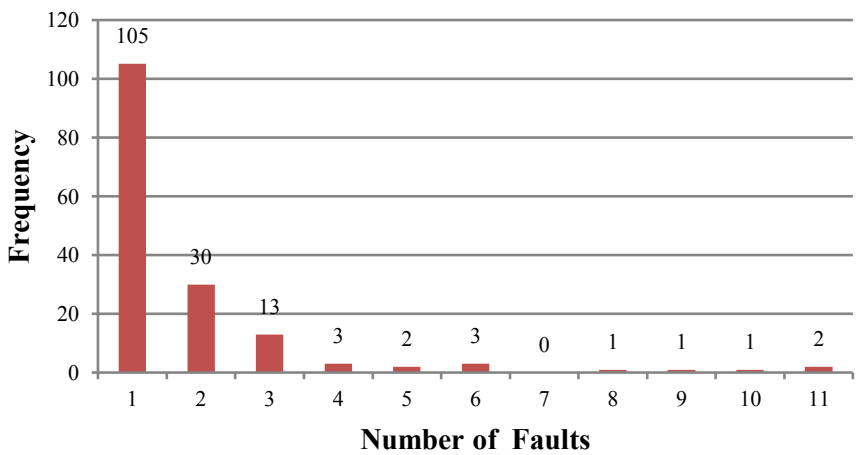

Fig. 4. Frequency distribution of size of lightning clusters

Faults due to lightning could be affected by projected changes in UK weather. Projections [8][12][13] suggest that lightning events are likely to occur more frequently in the UK, due to an increase in days with stronger convection, this would lead to an increase in the number of faults due to lightning. However, as noted above, the circuit outage duration associated with a lightning related fault is typically very short.

\section{Faults due to wind, gales, and windborne objects}

In Fig. 5, the cluster sizes for wind, gale, and windborne objects, it can be seen that there are four large clusters (with two particularly large).

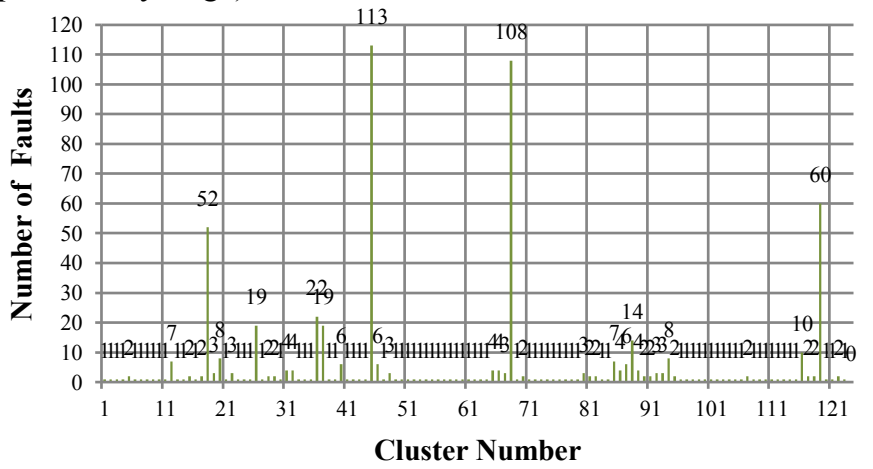

Fig. 5. Clusters in wind, gale, and windborne objects data

One of the largest events (cluster \#45) was caused by a storm which affected the area around the Hunterston nuclear station in the west of Scotland in 1998. The other large event (cluster \#68) was caused by a storm affecting first the Windyhill grid supply point, and Whitelee wind farm in the west of Scotland, then later the Cockenzie coal-fired power station, and the Torness nuclear power station located on Scotland's east coast. That is, it could be seen to traverse the whole of the south of Scotland from west to east over the course of 7 hours with wind speed remaining high enough to cause faults throughout that time.

Fig. 6 shows a frequency distribution of the wind, gale, and windborne objects clusters. It has a similar shape to the previous weather types, showing a majority of events causing a single fault, several causing two, and less causing greater than two.

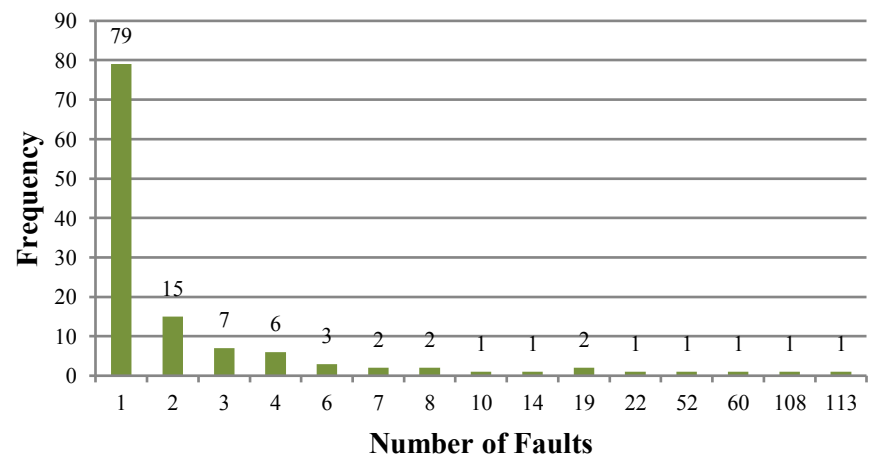

Fig. 6. Frequency distribution of size of wind, gale, and windborne objects clusters

Wind events account for the almost half of the weather related events recorded in the fault data, and include significantly sized clusters. There is a strong correlation between both wind speed and wind gusts and fault occurrences[9]. In particular faults are most likely when wind gusts of over $15 \mathrm{~m} / \mathrm{s}$ are observed. If climate change causes an increase in the probability of wind gusts over $15 \mathrm{~m} / \mathrm{s}$, then there is likely to be a sizable increase in the number of faults. The exact effect that climate change is likely to have on wind speeds in the UK has not yet been fully determined [2][8]. As with ice, snow, sleet or blizzard related faults, particularly high wind speeds can cause mechanical damage in which case the circuit restoration time can be expected to be very long.

\section{Faults due to salt, corrosion, and condensation}

Weather related salt, corrosion, and condensation events are generally caused by salt build-up on insulators, which causes flashover during mist or rain. As can be seen from Fig. 7, there is one large cluster, \#23 containing 47 faults. This is likely to have been caused by a large salt build up on the circuits around the Hunterston nuclear power station, located on the west coast of Scotland, during the same 1998 storm as the wind, gale, and windborne objects cluster \#47. During rain the following day, a large number of salt-related flashover events were seen and formed cluster \#23.

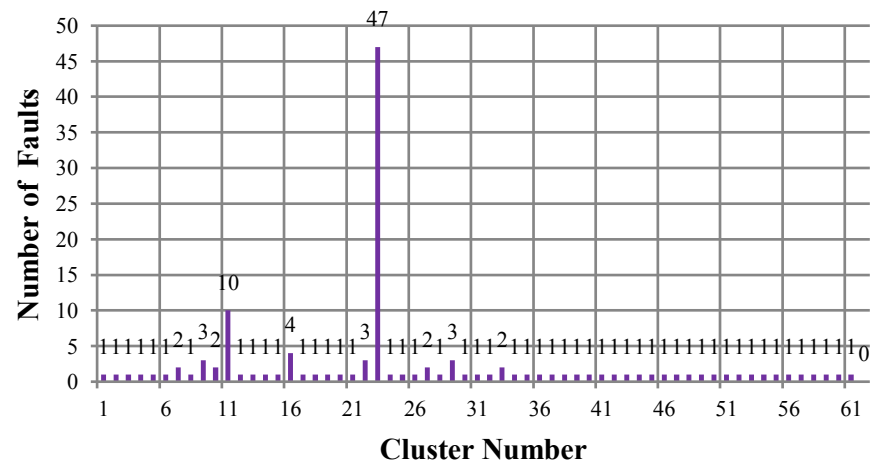

Fig. 7. Clusters in corrosion, condensation, and salt data.

From Fig. 8, the frequency distribution, it can be seen that the majority of clusters contain only one fault, with only 10 of the 61 clusters consisting of greater than this. 


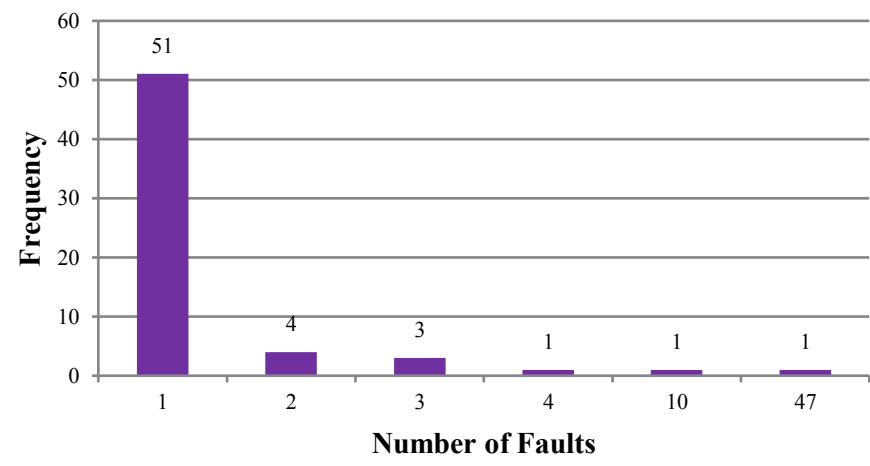

Fig. 8. Frequency distribution of size of corrosion, condensation, and salt clusters

Precipitation is likely to increase in the UK from climate change in the coming years. As the majority of weather-related salt faults are caused in part by the wind, this is another area where an increase in wind speed has the potential to increase faults. However as discussed above, the likely impact of climate change on wind speeds is inconclusive.

\section{DURATION OF CLUSTERS}

The duration of the clusters was also investigated. This was calculated from the time of the start of the first fault outage in the cluster until the start of the last fault outage in the cluster, and was taken as an indication of the period of time a weather event was causing fault outages. For clusters with a single fault the duration was taken from the fault occurring to the circuit restoration. Around 44\% of the weather-related faults detailed in the data were permanent faults, with the rest being transient.

Of the clusters which contained more than 1 fault: ice, snow, sleet and blizzard clusters had an average of 11.4 faults per hour (standard deviation 25.2); lightning clusters had an average of 8.4 faults per hour (standard deviation 16.2); wind, gale, and windborne object clusters have an average of 18.6 faults per hour (standard deviation 72); and corrosion, condensation and salt clusters have an average of 6 faults per hour (standard deviation 11.4).

\section{A. Faults due to ice, snow, sleet and blizzards}

Fig. 9 shows the duration of the ice, snow, sleet and blizzard clusters. As can be seen, some clusters contain only transient faults, which are cleared within seconds, other events clearly last for many hours. The longest events do not necessarily cause the most faults, however, suggesting that shorter, more intense weather events might be a more significant problem.

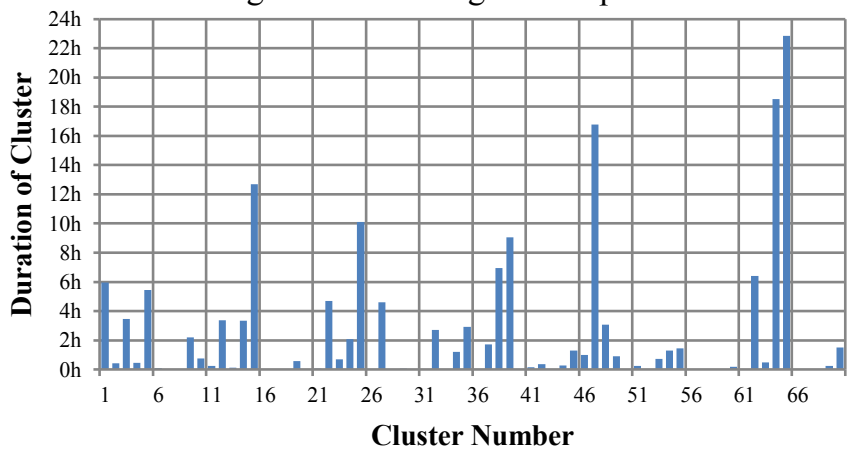

Fig. 9. Duration of ice, snow, sleet, and blizzard clusters

A frequency distribution of the ice, snow, sleet and blizzard fault clusters is shown in Fig. 10. The most common duration for an event of this type is up to four hours, followed by those cleared instantly, with a small number occurring from 4-24 hours.

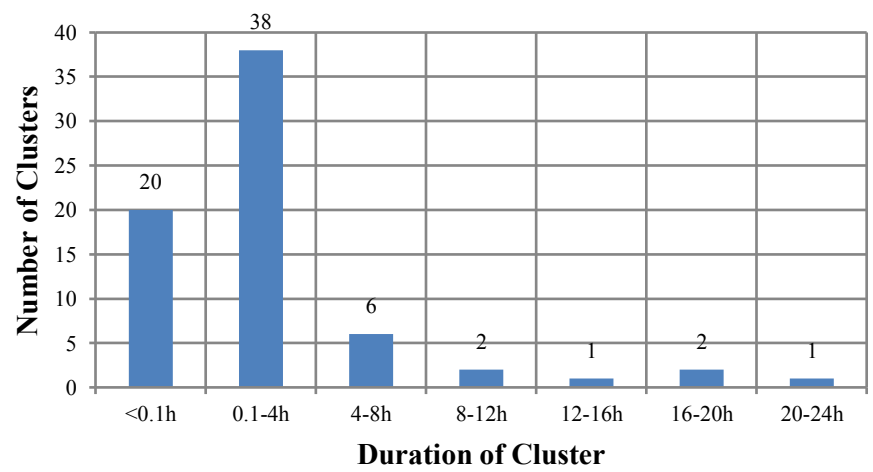

Fig. 10. Frequency distribution of ice, snow, sleet, and blizzard cluster durations

The total duration of ice, snow, sleet and blizzard clusters is 164 hours, which represents $0.07 \%$ of the time covered by the data.

\section{B. Faults due to lightning}

Lightning fault cluster durations, shown in Fig. 11, in general are shorter than ice, sleet snow and blizzard clusters.

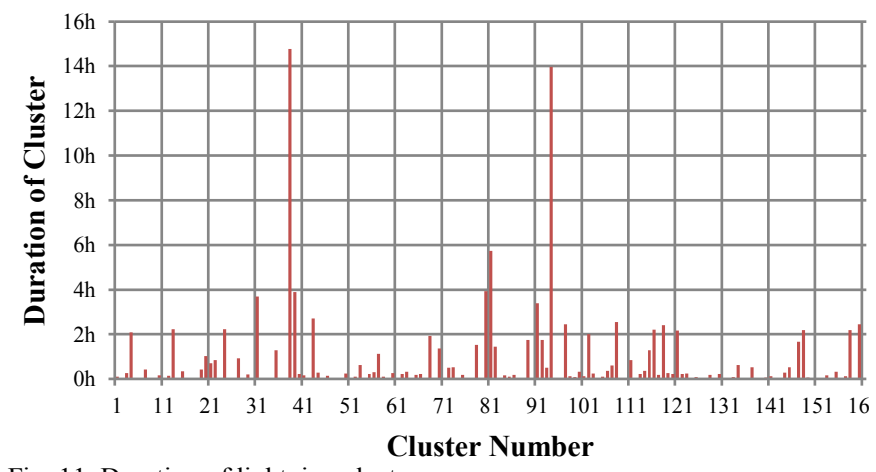

Fig. 11. Duration of lightning clusters

No events last longer than 16 hours, and most are transient, or last for only 1 or 2 hours. This is likely due to the behaviour of lightning storms. In general, lighting cluster duration increasing with the number of associated faults, but some outlier clusters comprising a large number of faults in a short time are also observed.

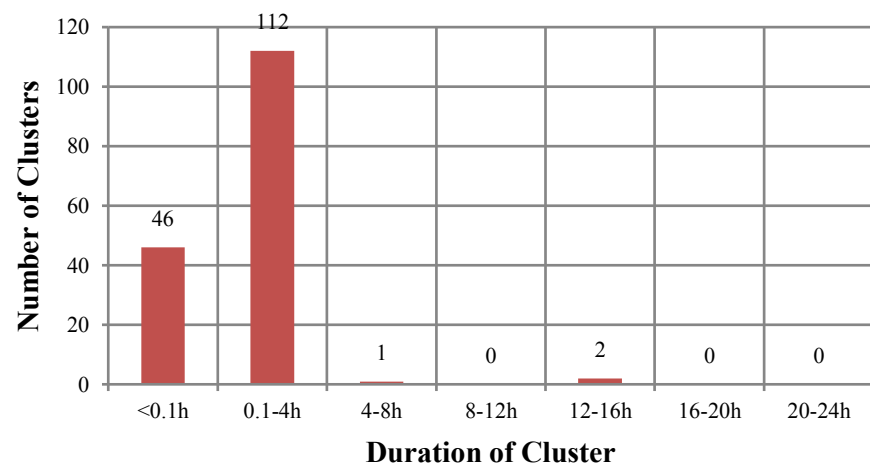

Fig. 12. Frequency distribution of lightning cluster durations

The frequency distribution of lightning cluster fault durations (Fig. 12) shows that, as with ice, sleet, snow and blizzard clusters, the majority last up to four hours again followed by those of minimal duration. This is more pronounced, however, with only 3 fault clusters lasting greater than 4 hours, and none lasting longer than 15 . 
The lightning fault clusters had a total duration of 114 hours, approximately $0.05 \%$ of the total time covered by the data.

\section{Faults due to wind, gales, and windborne objects}

Fig. 13 shows the wind, gale, and windborne objects cluster durations. The clusters of this type tend to last longer than the lightning clusters, although not as long as the ice, snow, sleet and blizzard clusters.

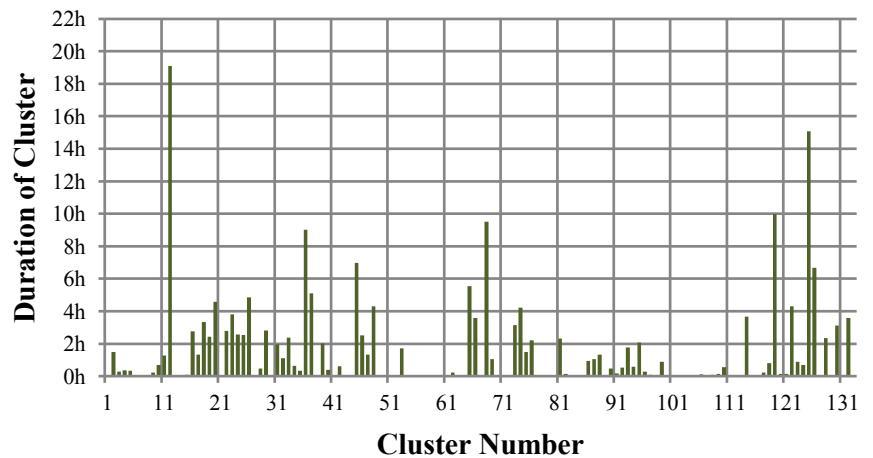

Fig. 13. Duration of wind, gale, and windborne objects clusters

From the frequency distribution, Fig. 14, it can be seen that, as with the previous fault types, the majority of clusters last up to 4 hours, followed by those of minimal duration. A few events last from 4 up to nearly 20 hours.

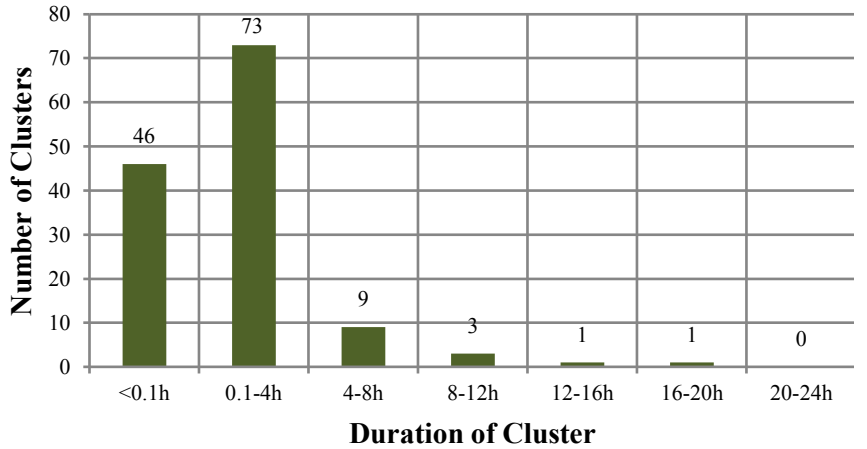

Fig. 14. Frequency distribution of wind, gale, and windborne objects cluster durations

The total duration of the wind, gale, and windborne objects clusters was 195 hours, approximately $0.08 \%$ of the total time of the years covered by the data.

D. Faults due to salt, corrosion, and condensation

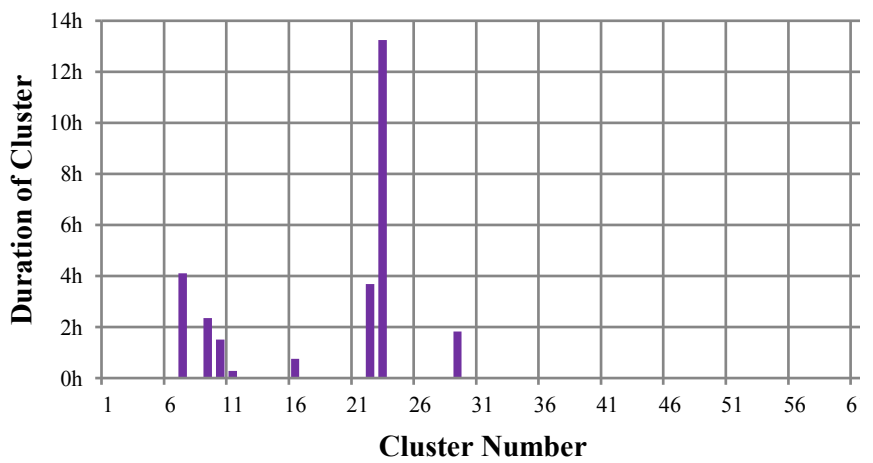

Fig. 15. Duration of corrosion, condensation, and salt clusters

The vast majority of salt, corrosion, and condensation cluster contain only a single fault, many of which are transient, therefore as can be seen from Fig. 15, the majority of clusters have no duration.
Unlike the other fault types, as can be seen in Fig. 16, very few clusters contain faults that are not transient, with only 6 clusters lasting up to 4 hours, and only 2 lasting beyond that.

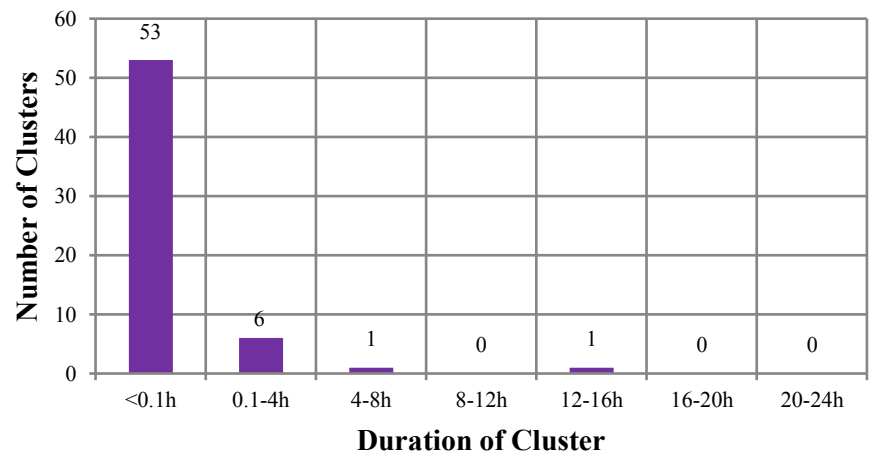

Fig. 16. Frequency distribution of corrosion, condensation, and salt cluster durations

The salt, corrosion, and condensation clusters had a total duration of 28 hours, approximately $0.01 \%$ of the total time of the years covered by the data.

\section{Spatial Extent of Clusters}

The spatial extent of each cluster, i.e., the likely area affected by the weather event which caused the faults in the cluster, was assessed. The affected area was estimated by first finding the centroid of the cluster by averaging the latitude and longitude of the mid-point of the affected substations [14]. The area was then defined as a circle with a radius connecting the centroid with whichever affected substation in the cluster was furthest from the centroid. For example, lightning cluster \#1, affected circuits connected to the substations of Bonnybridge (lat. 55.0079 long. -3.86042), Kincardine (lat. 56.0753 long. 3.72997) and Stirling (lat. 56.1178 long. -3.91906), giving a centroid of lat. 56.067 long. -3.83648 . The furthest affected substation from this is Bonnybridge, giving a radius of 16.92 $\mathrm{km}$, and therefore an estimated geographical area for lightning cluster \#1 of $900 \mathrm{~km}^{2}$ with a diameter of $34 \mathrm{~km}$. This gave an approximate area for comparison purposes, although did have the potential to overstate the true geographic extent of the weather event which caused the faults within the cluster.

\section{A. Faults due to ice, snow, sleet and blizzards}

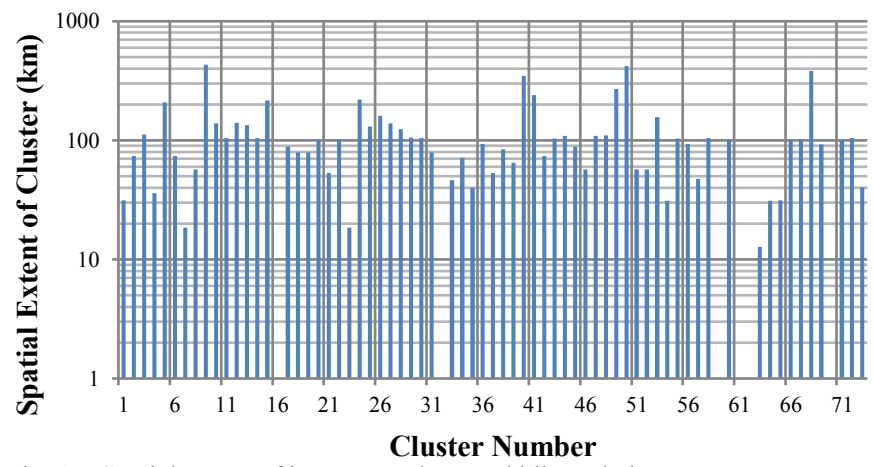

Fig. 17. Spatial extent of ice, snow, sleet, and blizzard clusters

Fig. 17 shows the logarithmic plot of the diameter of the spatial extent, as defined above, of each of the ice, snow, sleet and blizzard clusters. Several of these clusters covered a large geographic area, with three clusters affecting a calculated area of over $100,000 \mathrm{~km}^{2}$ which, if circular, would have a diameter of $360 \mathrm{~km}$ 


\section{B. Faults due to lightning}

From Fig. 18 (the spatial extent of the lightning clusters) it can be seen that the largest calculated area of the lightning clusters was greater than that of the ice, snow, sleet, and blizzard clusters. As the lightning clusters on average contained fewer faults, this suggests that lightning events are more spread out than ice, snow, sleet and blizzard events.

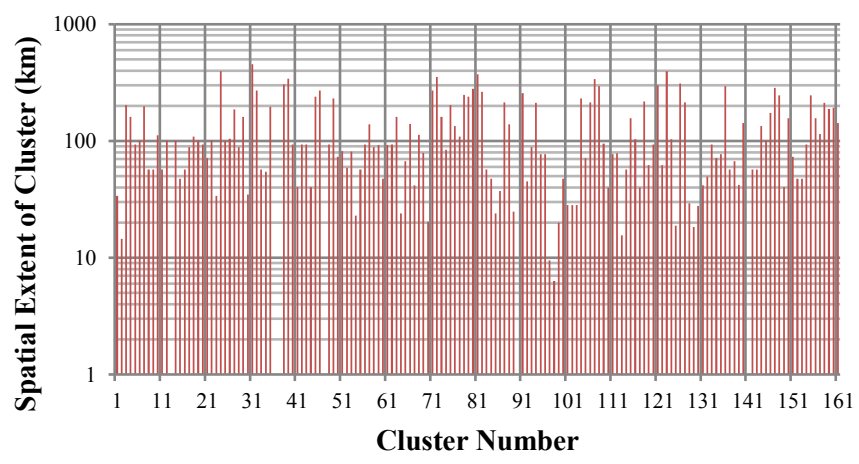

Fig. 18. Spatial extent of lightning clusters

\section{Faults due to wind, gales, and windborne objects}

The wind, gale, and windborne objects clusters which affected the largest areas (shown in Fig. 19) were larger again than either ice, snow, sleet, and blizzard clusters, or the lightning clusters. Comparing these values with the number of faults in the wind, gale, and windborne object clusters suggests that when wind events occur they effect a large geographic area, and effect a greater number of circuits in the area in which the weather event is occurs than lightning storms or blizzards.

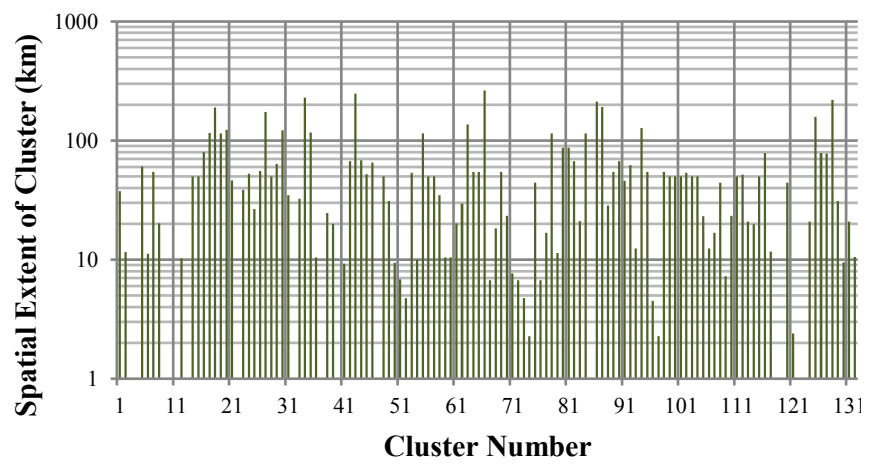

Fig. 19. Spatial extent of wind, gale, and windborne objects clusters

\section{Faults due to salt, corrosion, and condensation}

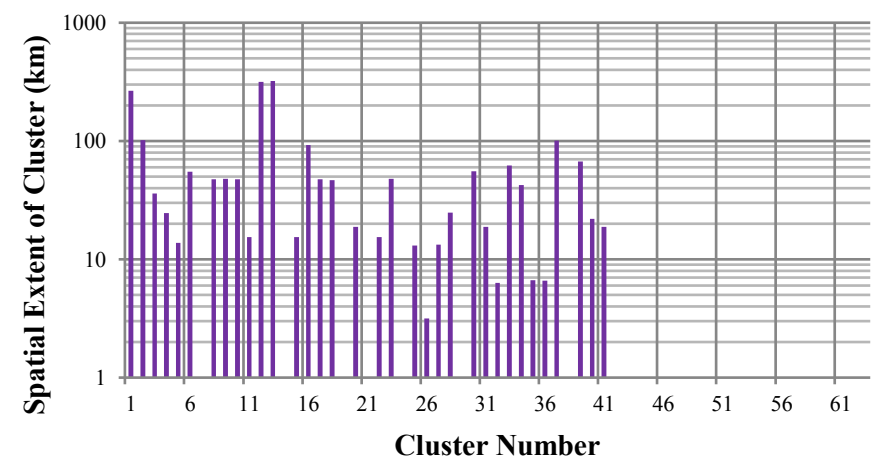

Fig. 20. Spatial extent of corrosion, condensation, and salt clusters

The majority of the salt, corrosion, and condensation clusters affected only one circuit, therefore the majority of the clusters do not have a calculated spatial extent, as can be seen in Fig.
20. The clusters of spatial extent with a diameter greater than $100 \mathrm{~km}$ (including cluster \#23), affected coast areas, likely due to a combination of wind and rain, as discussed in section III. A summary of the spatial extent of the clusters can be seen in Fig. 21, which shows a comparison of the cumulative frequency distributions of the cluster diameters by fault type.

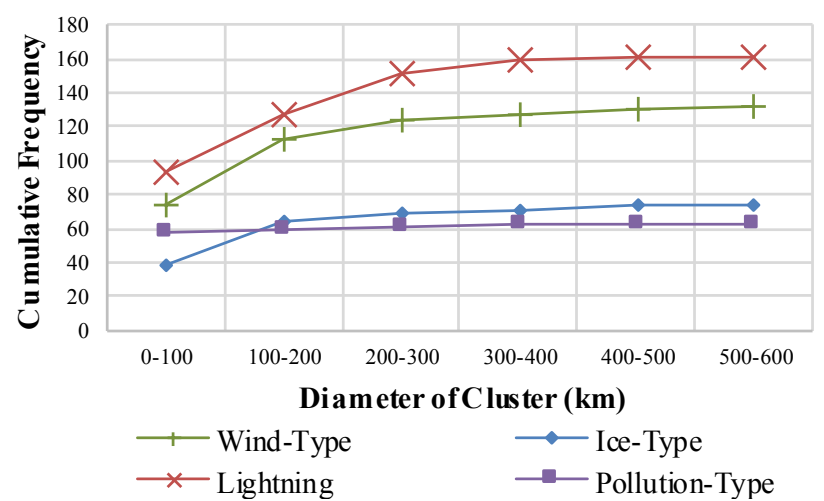

Fig. 21. Cumulative frequency distributions of cluster diameters by fault type

\section{DISCUSSION}

\section{A. Fault durations and rate of occurrence}

Analysis was presented in section III of the spread of fault durations, i.e. the time taken for each faulted circuit to be returned to service, in each weather category and the rate of occurrence of both transient (where the circuit is returned to service is less than a minute) and sustained faults in each cluster.

Given that transmission system operators typically operate to defined security standards, e.g. "N-1", there should normally be no significant adverse impact of a single fault event. (The system operator in GB is obliged to comply with the Security and Quality of Supply Standard[15]). However, the importance of weather events in which a number of faults might occur within a relatively short space of time is that, for sustained faults on circuits that have not yet been restored to service, it might not have been possible to re-secure the system before a second or third fault occurs. That is, the system is exposed to N-2 or N3 situations against which it is not normally configured to be automatically secure. Under these situations, the system is much more vulnerable to thermal overloads, voltage excursions or instability and, in a worst case, is exposed to the possibility of cascading outages. Thus, especially for weather types that involve quite rapid occurrence of sustained faults, the risk of interruptions to demand can be high. Furthermore, the occurrence of multiple faults that require repair or other on-site response within a short space of time places a large burden on the field staff. In severe weather, this can be compounded by the same weather making access to site very difficult.

In the analysis conducted in this study, it has been found that for wind, gale, and windborne object events, ice, snow, sleet and blizzard events, and lightning events are more likely to include multiple circuits than not, with over $50 \%$ of clusters found to affect more than 2 circuits. $15 \%$ of all wind type, and $18 \%$ of all blizzard- and lightning-type clusters affect more than 5 circuits. Over $5 \%$ of both wind-type and blizzard-type affect more than 10 circuits. In contrast only $40 \%$ of salt, corrosion 
and condensation events affected more than 2 circuits, with less than $5 \%$ affecting more than 5 . Given this, as the average ice, snow, sleet and blizzard fault has a return-to-service time of approximately 2 hours (compared to approximately 30 minutes for wind, gale or windborne object and lightning faults), from this analysis it is these type of faults which provide the greatest likelihood of multiple circuits being subject to faults simultaneously. Wind type faults also appear to provide a risk of simultaneous faults, as wind type clusters were found to have the highest number of faults per hour (18.6 per hour as discussed in section III compared with a year-round average rate of occurrence for the SPEN transmission area due to any type of fault of 0.006 per hour).

Comparing fault rates (including single-fault clusters) during adverse and non-adverse weather, highlights the increased likelihood of concurrent faults during storm conditions.

TABLE 1. OCCURRENCE OF FAULTS

\begin{tabular}{|l|l|l|l|}
\hline \multicolumn{1}{|c|}{ Weather } & $\begin{array}{c}\text { Total time } \\
\text { (hours) }\end{array}$ & $\begin{array}{l}\text { Number } \\
\text { of faults }\end{array}$ & $\begin{array}{c}\text { Occurrence } \\
\text { of faults } \\
\text { (faults/hour) }\end{array}$ \\
\hline Wind, etc. & 195 & 619 & 3.17 \\
\hline Snow, etc. & 164 & 436 & 2.65 \\
\hline Lightning & 114 & 293 & 2.55 \\
\hline Salt, etc. & 28 & 129 & 4.57 \\
\hline Non-adverse & 222867 & 1007 & 0.00451 \\
\hline
\end{tabular}

From Table 1, it can be seen that the fault rate during nonadverse weather is three orders of magnitude lesser than during adverse weather conditions.

\section{B. Potential impact of climate change}

From the above data, it is possible to categorise the different fault types by their past impact and probability. Fig. 22 summarises the key differences between the four fault-causing weather types. The average number of events per cluster also gives a suggestion of the number of extreme weather events in each category. These events were not excluded from the average, as they have the most impact on the network.

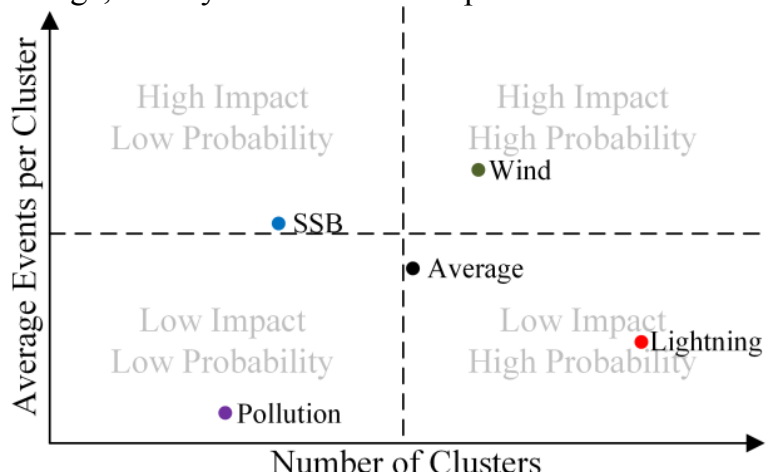

Fig. 22. Impact assessment of historic weather-type events

The potential future impact of fault-causing weather was also assessed (Fig. 23). For this it was assumed that ice, snow, sleet and blizzard events would become less likely, as in [5] and [8], lightning events would increase, as in [8], and that wind, gale, and windborne objects would either increase, decrease or stay the same as in [2] and [5] assuming that an increase in wind storms will see increases in wind speeds over $15 \mathrm{~m} / \mathrm{s}[9]$.

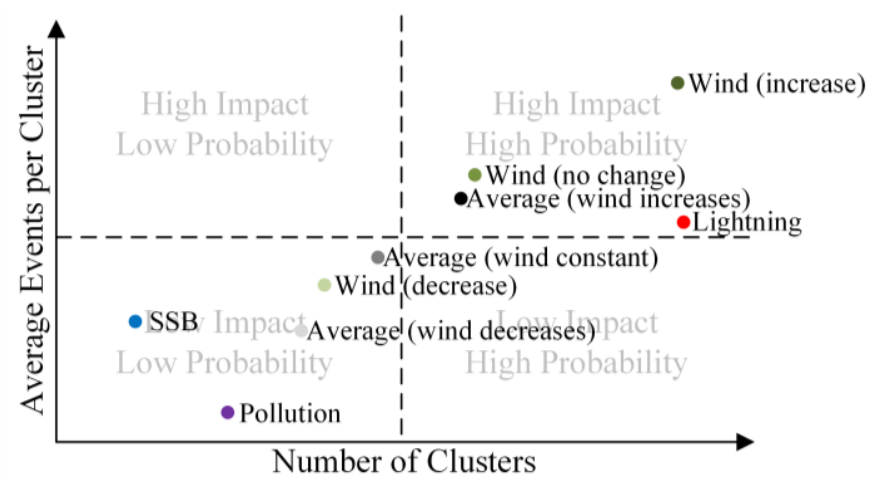

Fig. 23. Projected impact assessment of future weather-type events

From this it can be seen that the average impact of any given weather event on the GB network is highly dependent on the manner in which climate change affects wind speeds.

\section{CONCLUSIONS AND FURTHER WORK}

This paper has looked at the past occurrence of various types of weather-related faults, in an attempt to establish patterns with a view to providing a broad assessment on how climate change may affect faults on the GB transmission network in the future. Different weather events were identified based on temporal clustering of faults from around 30 years' worth of fault records for the south of Scotland. Each cluster was then assessed in respect of its duration, the number of faults in each cluster and the spread of durations of individual outages and the spatial extent of the cluster.

In the case of faults due to ice, snow, sleet and blizzard, it is likely that the overall number of these in GB is likely to decrease, with an overall decrease in the number of snow days, and days when the temperature falls below $0{ }^{\circ} \mathrm{C}$. The impact of these on the network at present can be quite dramatic, with occasional snow causing fault outages over a period several hours. Their decrease would entail reduced risk in system operation.

The conditions for lightning events are likely to become more prevalent in the UK in the future. Although these events do not seem to cause large clusters of faults, they do appear more likely to cause a greater number of faults in a shorter time than other weather events. Therefore, an increase in lightning would see a small increase in the number of transmission faults and increase the likelihood of simultaneous faults, with an overall negative effect on the network. This would likely be offset, however, by the decrease in ice, sleet, snow and blizzard events which tend to be both more frequent and have a higher impact.

The biggest potential impact on the network comes from any impact on wind speeds. If there were to be a significant increase in wind speeds, and extreme wind events, this would clearly cause a noticeable increase in transmission faults. However, it may also lead to more frequent occurrence of mechanical damage and, as a consequence, longer restoration times which will leave the system more exposed to N-2 or N-3 situations. If the system has not been re-secured in the meantime, cascades of outages and widespread disconnection of demand might result. Wind is also a factor in salt pollution on lines causing flashover. Conversely, if wind speeds were to remain roughly 
constant, or even to decrease then the overall impact of climate change on the GB network would likely be minimal, and could even represent a slight benefit in respect of risk associated with faults.

Future work should concentrate on how wind speeds are likely to be affected as the climate changes. From this it should be possible to forecast the overall impact of climate change on Britain's transmission grid. The system is more likely to suffer breaches of operational limits when faults occur not only close to each other in time but also in space, e.g. two or more outages on circuits crossing a system boundary are more likely to lead to disconnection demand or an overload on the remaining crossboundary circuits. The work reported here has considered only one relatively small region of GB so it has not been possible to make substantive comments on the spatial extent of weather related events in Britain as a whole. This should be addressed in future work.

Other work should analyse in more detail the actual impacts associated with future patterns of weather. This can be done through sampling of weather events and of faults associated with each event and, in a manner similar to that described in [16], simulation of the power flows and stability of the system in each outage condition. This can then inform whether changes to, for example, tower design or security standards might be necessary to manage the impacts of changed weather.

Finally, the kind of analysis of faults undertaken here for weather-related faults might also be carried out for faults not noted in the fault records as weather-related. For example, is it possible that some faults that are supposedly not weather related might actually be indirect consequences of weather or of prior events caused by adverse weather? Or, what evidence is there for something that is sometimes speculated on, that fault outages occur more often in the maintenance outage season or in proximity to where maintenance or construction work is being carried out?

\section{ACKNOWLEDGEMENT}

The authors would like to thank Ms Kirsty Murray for her work on categorising the fault data into weather types, and for support and suggestions for the direction of the project, SP Energy Networks, for access to their fault data for the project, and the Centre for Environmental Data Archival for access to historic Met Office data.

\section{REFERENCES}

[1] D. M. Ward, "The effect of weather on grid systems and the reliability of electricity supply," Clim. Change, vol. 121, no. 1, pp. 103-113, 2013.

[2] UK Met Office, University of Nottingham, Walker Institute, Centre for Ecology \& Hydrology, University of Leeds, and Tyndall Centre for Climate Change Research, "Climate: Observations, projections and impacts - United Kingdom," 2011.

[3] IPCC Working Group III, "Special Report Emissions Scenarios," 2000.

[4] D. Yates et al., "Stormy Weather - Assessing Climate Change Hazards to Electric Power Infrastructure: A Sandy Case Study," IEEE Power and Energy Magazine, no. September/October, pp. 66-75, 2014.

[5] J. Lassila, T. Kaipia, J. Haakana, and J. Partanen, "Major Blackouts in the Development of Electricity Distribution Networks," 2014 IEEE PES Gen. Meet. - Conf. Expo., pp. 1-5, 2014.

[6] L. M. Beard et al., "Key technical challenges for the electric power industry and climate change," IEEE Trans. Energy Convers., vol. 25, no. 2, pp. 465-
473, 2010.

[7] B. Nordell and B. Gervet, "Global energy accumulation and net heat emission," Int. J. Glob. Warm., vol. 1, no. 1, pp. 378-391, 2009.

[8] L. McColl, E. J. Palin, H. E. Thornton, D. M. H. Sexton, R. Betts, and K. Mylne, "Assessing the potential impact of climate change on the UK's electricity network," Clim. Change, vol. 115, no. 3-4, pp. 821-835, 2012.

[9] K. Murray and K. R. W. Bell, "Wind Related Faults on the GB Transmission Network," in 2014 International Conference on Probabilistic Methods Applied to Power Systems (PMAPS), 2014, pp. 1-6.

[10] ScottishPower Energy Networks, "SPEN - Our Transmission Network." [Online].

Available: http://www.spenergynetworks.co.uk/pages/our_transmission_network.asp [Accessed: 02-Jul-2015].

[11] National Grid, "Electricity Ten Year Statement - Appendix A1: System Schematics." pp. 1-8, 2015.

[12] Met Office, "Assessing the potential impact of climate change on the UK' s electricity network," p. 2, 2012.

[13]D. M. Romps, J. T. Seeley, D. Vollaro, and J. Molinari, "Projected increase in lightning strikes in the United States due to global warming," Science (80-. )., vol. 328, no. 2009, pp. 851-856, 2013.

[14] National Grid, "Electricity Ten Year Statement - Appendix B: System Technical Data." 2015.

[15] National Grid, National Electricity Transmission System Security and Quality of Supply Standard. 2012.

[16]D. S. Kirschen, K. R. W. Bell, D. P. Nedic, D. Jayaweera, and R. N. Allan, "Computing the value," no. 488, pp. 35-40, 2002.

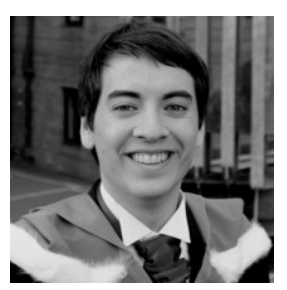

\section{BIOGRAPHIES}

Euan A. Morris (StM '15) was born in Glasgow, Scotland, in 1991. He received the MEng. degree in electrical and electronic engineering with business studies from the University of Strathclyde, Glasgow (including an exchange year to Nanyang Technological University, Singapore), in 2014 and is currently undertaking the Ph.D. degree at the EPSRC Centre for Doctoral Training in Future Power Networks and Smart Grids, run by the University of Strathclyde, Glasgow and Imperial College London, London. He was a Scholar at the IET Power Academy, sponsored by ScottishPower Energy Networks, from 2010 to 2014 and undertook summer work with the company during these years in and around Glasgow, Scotland.

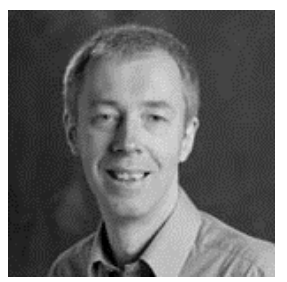

Keith Bell is the ScottishPower Professor of Smart Grids at the University of Strathclyde. He joined the University in 2005 having previously gained his $\mathrm{PhD}$ at the University of Bath and worked as an electrical engineering researcher in Manchester and Naples, and as a system development engineer in the electricity supply industry in Britain. $\mathrm{He}$ is Chartered Engineer, a co-Director of the multidisciplinary UK Energy Research Centre (UKERC), an invited expert member of CIGRE Study Committee C1 on System Development and Economics and a member of the Council of the IET Power Academy, an initiative to promote electric power engineering as a graduate career in the UK.

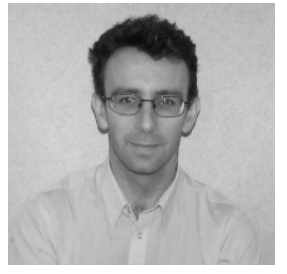

Ian Elders received his BEng degree in electronic and electrical engineering and $\mathrm{PhD}$ degree in electrical power engineering from the University of Strathclyde, Glasgow, UK in 1994 and 2002 respectively. He is currently a Research Fellow within the Institute for Energy and Environment at the University of Strathclyde, with a particular interest in the planning, operation and monitoring of power networks incorporating Smart Grid technologies. He has previously undertaken research in collaboration with South West Electricity, National Grid, Rolls-Royce and ScottishPower. 